\title{
Políticas de Saúde no Brasil, continuidades e mudanças
}

\author{
Cristiani Vieira Machado, Tatiana Wargas de Faria Baptista \\ e Luciana Dias de Lima (Orgs.), Editoria Fiocruz, 2012
}

Resenha por: Lucas Hernandes Corrêa*

\section{Introdução}

O livro traz a proposta de retratar um período político, apesar de sua natureza intrinsecamente dinâmica e interdependente, através da análise de políticas públicas implementadas na área da saúde. O período corresponde aos dois mandatos do presidente Luiz Inácio Lula da Silva (2003 a 2006 e 2007 a 2010) e se justifica pela promessa que esse governo trouxe de inclusão social e aperfeiçoamento democrático, ambos muito caros ao Sistema Único de Saúde (SUS) e aos seus idealizadores.

A obra está estruturada em três partes. A primeira, Contexto, de forma geral, trata da relação entre saúde e economia, sob três aspectos: políticas sociais (não) implementadas dentro de modelos econômicos diversos (capítulo 1), a saúde como setor produtivo (capítulo 2) e a saúde como bem, consumível no mercado privado (capítulo 3). A segunda, Caminhos, faz referência às estratégias para efetivação do SUS: a forma de intervenção do Estado (capítulo 4), a agenda federal (capítulo 5), a atenção primária (capítulo 6) e o trabalho e a educação em saúde (capítulo 7). A terceira e última, Processos, apresenta propostas de estruturação do SUS, dentre elas a descentralização e a regionalização (capítulo 8), a gestão estratégica e participativa (capítulo 9) e a atuação do legislativo (capítulo 10).

A análise do livro foi dividida de acordo com as ideias gerais depreendidas de cada uma de suas partes, obedecendo a ordem estabelecida na obra e a sequência dos capítulos.

\footnotetext{
* Mestre em Direito da Saúde, Université Paris X - Nanterre; Mestre em Políticas de Saúde, London School of Hygiene and Tropical Medicine and London School of Economics. Consultor na área de saúde e ciências da vida na Prospectiva Consultoria. Advogado. São Paulo/SP-Brasil. E-mail: Icorrea@prospectiva.com 


\section{Saúde e mercado}

O tema é relevante, pois o próprio artigo 196, da Constituição Federal, condiciona a garantia e a efetivação do direito à saúde à implementação de políticas nas áreas social e econômica. Os textos da primeira parte do livro sugerem que a forma ou a intensidade com que isso é buscado pelos governos estaria relacionada aos modelos de desenvolvimento adotados, refletindo na forma de atuação do Estado.

No capítulo 1, o primeiro mandato do presidente Lula é identificado como um período de transição entre o modelo neoliberal (governos Fernando Collor, Itamar Franco e Fernando Henrique Cardoso) e o modelo novo desenvolvimentista, já caracterizado no segundo mandato. Ter-se-ia, assim, caminhado do contexto de Estado mínimo, que privilegiou o livre comércio e valorizou as liberdades individuais, no qual a política social se resumiu ao assistencialismo àqueles incapazes de satisfazer as suas necessidades mais básicas, para um contexto de Estado robusto, atuante na geração de emprego e renda, e focado na redução das desigualdades sociais.

Na prática, sob a vigência do modelo neoliberal, o orçamento da seguridade social (OSS) foi desmontado, comprometendo o financiamento da saúde; a participação de atores privados na prestação de serviços de saúde foi também estimulada através de figuras jurídicas do terceiro setor, como as Organizações Sociais (OSs) e as Organizações da Sociedade Civil de Interesse Público (OSCIPs). Nele também começaram a ser implementados os programas de transferência de renda (bolsa escola, alimentação e auxílio gás) e a estratégia de saúde da família (ESF); foram criadas a Agência Nacional de Vigilância Sanitária (Anvisa) e a Agência Nacional de Saúde (ANS), deu-se início à política de produção doméstica de medicamentos genéricos e foi iniciado o processo de descentralização dos serviços de saúde para Estados e municípios.

Durante a transição foi dada continuidade à maioria das políticas do modelo anterior, mas sem a preocupação de reverter as mudanças ruins que foram introduzidas. A descentralização foi aprimorada através da pactuação entre os entes federados, bem como a transferência de recursos com a criação dos blocos de financiamento do SUS e a criação de programas pontuais. Já no período novo desenvolvimentista, o Estado consolidou seu protagonismo com relação ao crescimento econômico do país, sendo as políticas industriais seu principal instrumento, ao lado do investimento em infraestrutura e o foco em ciência e inovação tecnológica.

A saúde foi sem dúvida colocada como um setor estratégico de atuação estatal, tal como revela o capítulo 2. Essa integração entre o aspecto econômico e social na estratégia de desenvolvimento do país através do setor de saúde é vista como um grande progresso. No entanto, os autores sugerem a equiparação do SUS a um grande mercado (de trabalho, de produtos e de inovações tecnológicas), pautado pelas demandas de saúde da população e que se relaciona com uma 
diversidade de setores produtivos. Tem-se a ideia de que o Estado consegue direcionar o lado da oferta, com base nas necessidades do SUS e do próprio país (lado da demanda).

Seria possível, assim, lidar com o problema do déficit tecnológico do país, que o obriga a importar produtos complexos e caros, o que impacta negativamente a balança comercial e o orçamento do Ministério da Saúde. Segundo os autores, essa situação gera dependência com relação a empresas estrangeiras, o que fragiliza a cobertura do sistema de saúde na medida em que variações cambiais e descontinuidades de produção, que são imprevisíveis, podem inviabilizar o acesso da população a esses produtos.

É dentro dessa lógica que é lançado o Programa Mais Saúde (PAC da Saúde), em 2007, que define o Complexo Econômico e Industrial da Saúde (CEIS), com o objetivo de solucionar esses problemas de forma integrada, garantindo a universalização do direito social à saúde e incluindo o Brasil na nova fronteira tecnológica, a da biotecnologia.

No entanto, ao analisar a questão sob o prisma do próprio conceito do direito à saúde, parece existir uma contradição nos argumentos utilizados em defesa do CEIS, no texto: fala-se na necessidade de superação do modelo medicalizante da saúde brasileira e dos problemas de financiamento e gestão do sistema. Por outro lado, a estratégia foca a produção nacional de produtos estratégicos como forma de viabilizar o seu acesso pela população. Além do custo, o foco na produção de bens ganha vida própria e se distancia do processo de produção da saúde.

Quando o texto fala sobre a necessidade de promoção do consumo de massa, ele assume o risco de confundir o direito à saúde como algo capaz de ser efetivado pelo mero acesso a bens de consumo, ainda que de importância para a recuperação da saúde. O direito à saúde é antes um direito de cidadania e a sua efetivação se dá primordialmente através do acesso ao cuidado adequado, que tem por foco o indivíduo compreendido na sua realidade particular e coletiva, e não como consumidor.

É nesse contexto que o capítulo 3 revela a existência de um aparato burocrático que possibilita aos principais atores da saúde suplementar brasileira consolidar seus negócios sem necessariamente ampliar a oferta de seus serviços, apesar da demanda crescente da população que, elevada a um status social virtualmente superior, não consegue encontrar no SUS a satisfação de suas demandas. A autora denuncia a complacência do governo com relação a esses atores econômicos e os incentivos diretos e indiretos colocados à sua disposição e mascarados pela atuação virtual da ANS.

\section{Estratégias para a efetivação do SUS}

Ao se voltar o olhar para a atuação do Ministério da Saúde durante o governo Lula (capítulo 4), constata-se a existência de um modelo híbrido, que manteve 
características gerencialistas, próprias do modelo neoliberal, com maior foco na regulação do mercado; mas também foram introduzidas características de inclusão democrática e de produção de insumos, próprias do modelo novo desenvolvimentista.

Isso indica que, apesar das promessas de ruptura com o modelo anterior, houve continuidades importantes dentro das políticas de saúde ao mesmo tempo em que não se propugnou por mudanças estruturais importantes para o aperfeiçoamento do SUS. Mesmo com a propositura de atuação unificada e coordenada, através de novos instrumentos de planejamento, não se conseguiu superar a fragmentação existente dentro da própria estrutura do Ministério da Saúde.

Somado à dificuldade de se trabalhar dentro da lógica de implementação descentralizada das políticas, o planejamento integrado no setor ficou comprometido. Isso favoreceu o protagonismo do Ministério em áreas aleatórias, nas quais a atuação de Estados e municípios se dá mais em virtude dos condicionantes financeiros do que em virtude da sua necessidade real.

Os autores atestam que essa forma de atuação se consolida graças à importância da União no arranjo federativo brasileiro, onde a capacidade arrecadatória dos entes está descolada das suas responsabilidades em relação à implementação dos serviços públicos. O subfinanciamento crônico do SUS e o decréscimo da participação financeira federal no setor reforçam essa relação de dependência do nível central. Aas políticas que acabam ganhando destaque, nesse contexto, são as em que o Ministério decide apostar suas fichas, esquivando-se do enfrentamento das deficiências estruturais do sistema de saúde.

Da análise da agenda federal da saúde (capítulo 5), como novidade, está o foco nas questões de recursos humanos e da produção de insumos. Em linha de continuidade estão políticas como:

- Samu, que em 2010 já abrangia 109 milhões de pessoas, em mais de 1.400 municípios;

- Farmácia Popular, que expandiu significativamente o acesso a medicamentos a preços subsidiados pela população através do aumento do número de farmácias conveniadas; e

- Brasil Sorridente, que fez com que o número de equipes de saúde bucal implantadas aumentassem de 4.261 para 20.424, num período de oito anos.

No campo da atenção à saúde (capítulo 6) fica evidente que, apesar da produção normativa, pouco se avançou no campo da atenção básica, com um crescimento apenas marginal da participação desse componente no orçamento do Ministério. Assim, o aumento do número de equipes de saúde da família não evidencia o reconhecimento da centralidade da ESF durante o governo Lula, contrariamente ao que afirmam as autoras.

Isso se justifica pelo fato de que, apesar de a atenção primária ter sido assunto recorrente na Comissão Intergestores Tripartite (CIT), entre 2003 e 2010, não 
se avançou nas formas de integrá-la à organização de redes regionalizadas. Assim como não se avançou nas discussões sobre a necessidade de formação de profissionais especializados em saúde da família, fragilizando, por exemplo, a ideia de apoio matricial das equipes através dos Núcleos de Apoio à Saúde da Família (NASF), como o próprio texto revela. Ao não lidarem com problemas estruturais do sistema como um todo, políticas de grande potencial perdem vitalidade, isso quando não atrapalham a implementação de outras políticas.

Nesse contexto, é interessante olhar para as políticas de trabalho e de educação em saúde implementadas pelo Ministério da Saúde (capítulo 7), já que o modelo neoliberal parece ter afetado sobremaneira as relações de trabalho no SUS, tal como demonstra o texto. Por um lado, houve a flexibilização das regras de atuação no setor público, com a possibilidade de coexistência de servidores estatutários, concursados e empregados celetistas dentro do mesmo local de trabalho. Também foi aberta a possibilidade de prestação de serviços públicos através de formatos jurídicos de direito privado, o que contribuiu inclusive para a precarização das relações trabalhistas na saúde.

Por outro lado, também foram criados limites com relação aos gastos com folha de salário por parte dos entes federados, como a Lei de Responsabilidade Fiscal (LRF). Isso impactou negativamente setores intensivos em mão de obra, como o da saúde. Essa situação, somada à falta de estruturas adequadas de trabalho dificultaram ainda mais a permanência de profissionais qualificados no SUS.

O texto mostra que Lula tentou de alguma forma reverter esse quadro, mas sem de fato o fazer. Ele investiu no aumento da capacidade do Estado, realizando concursos públicos e substituindo os terceirizados. Mas dada a insuficiência de investimentos na saúde, ele apoiou a criação de fundações estatais e de uma empresa de serviços hospitalares justamente para driblar os gastos e as obrigações geradas pelo modelo de Estado propugnado e continuado por ele próprio.

Assim, não é difícil imaginar que a criação de uma Secretaria dentro do Ministério para tratar das questões ligadas ao trabalho e à educação em saúde, a Secretaria de Gestão do Trabalho e da Educação na Saúde (SGETS), tenha alcançado resultados insuficientes. A disponibilidade de recursos nesse campo - com a criação do bloco de financiamento da gestão em 2008 - acabou pressionando Estados e municípios a implementar atividades de capacitação, sem qualquer contrapartida de melhoria nos serviços e na dinâmica de trabalho, já que elas não garantem a superação de constrangimentos estruturais e institucionais da gestão pública.

\section{Estruturação do SUS}

Sob a força do princípio constitucional da integralidade, é proposta uma nova dinâmica de organização dos serviços de saúde que supera os limites geográficos dos entes federados, fazendo com que a repartição de competências e 
responsabilidades se dê de forma pactuada e seja mutável no tempo. O capítulo 8 , nesse sentido, revela que essa lógica foi colocada em prática de forma mais consolidada a partir de 2006 com o Pacto pela Saúde, onde ganha destaque a atuação dos Colegiados de Gestão Regional (CGRs).

A adesão dos entes federados ao Pacto acabou sendo muito desigual no país, na medida em que não foi acompanhada de maior atuação do nível central justamente para contrabalancear o peso dessas desigualdades. Em muitos locais, a adesão se deu de forma cartorial e burocrática, como revelam os autores. Mesmo nos lugares onde as pactuações ocorreram, com o suporte dos colegiados, elas não alteraram o volume de recursos nem ampliaram a autonomia dos gastos dos entes, acabando por burocratizar e fragmentar a implementação das políticas de acesso aos serviços assistenciais à saúde.

Ao se pensar em formas mais efetivas de intervenção nas diferentes realidades locais, chama a atenção o capítulo 9, que trata da Secretaria de Gestão Estratégica e Participativa do Ministério, cuja atuação deveria girar em torno da participação da comunidade na implementação, gestão e controle do SUS, propugnada pela própria Constituição. No entanto, conflitos político-ideológicos e disputas por espaço ao lado do ministro fizeram com que a Secretaria demorasse a se consolidar. Apesar disso, a participação social no SUS foi institucionalizada, principalmente através do ParticipaSUS, mas sem maiores resultados práticos.

A própria ideia de participação democrática coloca em destaque a atuação do poder Legislativo nas questões concernentes à saúde. Assim, o capítulo 10 se debruça sobre a forma como as demandas na área são vocalizadas pelo Congresso. Não diferente daquilo que se observou até agora para o Executivo, as autoras concluem para a falta de clareza quanto ao projeto de saúde pública entre os congressistas. Como resultado, vêm se deixando em aberto questões de extrema importância, como o financiamento do SUS e a participação do setor privado na saúde.

O texto demonstra que o modelo constitucional do SUS é constantemente deixado de lado, em privilégio a interesses de grupos específicos, que ficaram ainda mais fortes na medida em que os setores do SUS e da saúde privada foram se expandindo, gerando tensões entre o modelo de saúde pública e o projeto privatizante da saúde.

No período que antecedeu o governo Lula, as autoras identificaram dois subperíodos de atuação, um de expansão de políticas específicas e técnicas na área da saúde e outro com maior ênfase na regulação do mercado em saúde. Já durante o governo Lula, o Executivo conseguiu impor sua agenda através de uma ampla coalizão partidária. Mas três tendências foram observadas: segmentação das demandas em saúde, demandas específicas que visam cobrir lacunas e aprimorar políticas em curso, e a criação de dias nacionais de prevenção de determinadas doenças e agravos. 


\section{Considerações finais}

O livro merece ser lido com senso crítico aguçado, pois, dado certo alinhamento ideológico com o período de governo analisado, alguns aspectos negativos das políticas consideradas são diminuídos e os positivos não são necessariamente seguidos de dados que os comprovem.

O que chama a atenção, entretanto, é que, de modo geral, a obra deixa claro que não existe um comprometimento com o projeto SUS, tanto pelos governos anteriores quanto pelo governo Lula, e, nesse sentido, há, infelizmente, uma grande continuidade. Percebe-se que as políticas implementadas não pertencem a um contexto maior, não se comunicam entre si dentro de uma linha de planejamento de médio e longo prazos. As realidades locais são desconsideradas e o impacto na saúde da população é deixado em segundo plano. Os governos parecem não saber o que querem do SUS. 